\title{
Recent trends in deal-making
}

Analysis of key trends in deal-making can help indicate the strategic directions in which the pharmaceutical industry overall is moving and thereby inform future decisions. With this in mind, here, we analyse data from PharmaVentures' PharmaDeals v4 on product deals incorporating all forms of therapeutics, vaccines, over-the-counter medicines and drug delivery technologies in all therapeutic areas between 2007 and the end of October 2010.

Considering total deal numbers first, there were 1,065 deals in 2007, 981 in 2008, 983 in 2009 and 839 in the first 10 months of 2010. This corresponds to an average of $89,82,82$ and 84 deals per month per year, respectively. There was clearly a greater level of deal-making activity in 2007, before the global financial crisis, than in the following years. The crisis emphasized a problem that the industry was already experiencing, in that reduced availability of equity finance was hampering biotechnology companies looking to develop drugs to the point of a licensing event. Although there is no substantial difference between 2008, 2009 and 2010, the trend seems to be upwards, with month on month increases from July 2010 onwards. Deals that were initiated by biotechnology companies facing a lack of funding a year or more ago are now coming to fruition. Good-quality projects are attracting equity funding, but the breadth of projects being funded this way is still reduced compared to previous years.

Pharmaceutical companies are still faced with the 'patent cliff', with the top ten pharmaceutical companies set to lose between $30 \%$ and $80 \%$ of revenue from key drugs over the next 5 years. Rising deal valuations reflected this pressure until 2009, presumably indicating increasing competition for the best assets. Average deal values rose from US\$155 million in 2007 to $\$ 180$ million in 2008 and $\$ 218$ million in 2009 , before falling back to $\$ 169$ million in 2010, perhaps as a result of larger numbers of assets becoming available from smaller resource-starved biotechnology companies, thus giving licensors more choice and driving values down. Recent major consolidation and merger and acquisition activity might also underlie this effect, particularly if large companies are focusing on integrating acquired portfolios rather than expanding the number of external alliances.

An indication of how deal-making is changing in different therapeutic areas year on year is provided in FIG. 1. The rapid decline in deal numbers in 2008 has bottomed out in most areas. However, some areas, including oncology, endocrine and metabolic diseases, and diseases of the nervous system, are showing signs of increasing deal activity. Oncology is the largest single therapeutic area for deals, accounting for at least $40 \%$ more deals than any other category. Overall, it seems that the slow recovery from the economic recession is still affecting the pharmaceutical and biotechnology industries, and that a consensus strategy has yet to emerge for delivering future growth.

\footnotetext{
Adrian Dawkes, Ph.D., is Senior Director, and Tibor Papp, M.D., Ph.D., is Head of Corporate Advisory at PharmaVentures, Florey House, Oxford Science Park, Oxford OX4 4GP, UK.

Correspondence to T. P. e-mail: tibor.papp@pharmaventures.com The authors declare no competing financial interests.
}

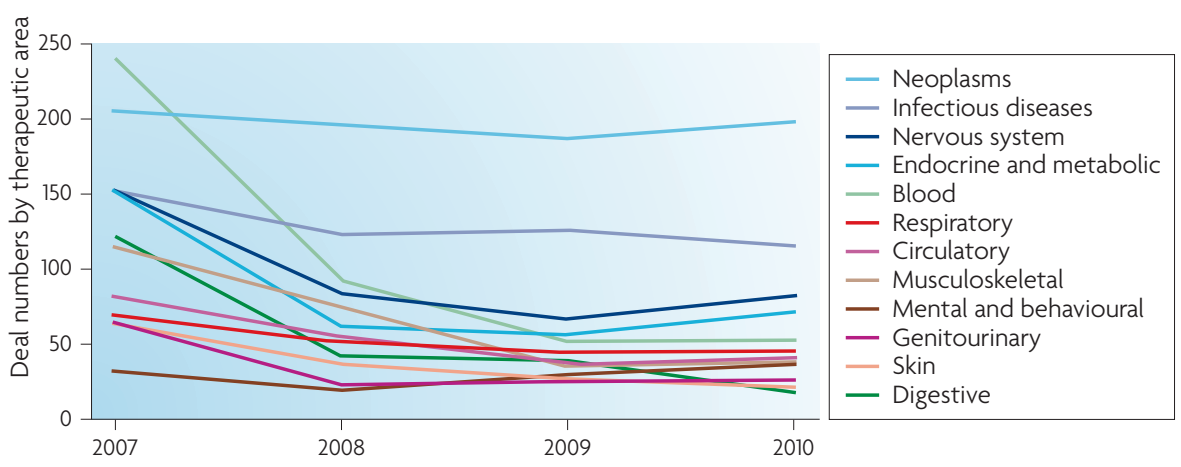

Figure 1 | Comparison of deal numbers according to therapeutic area. These data have been normalized to account for 2010 being an incomplete year. Source: analysis of Pharmaventures', PharmaDeals v4. 